\title{
PET Tau and Amyloid- $\beta$ Burden in Mild Alzheimer's Disease: Divergent Relationship with Age, Cognition, and Cerebrospinal Fluid Biomarkers
}

Ivan Koychev, Roger N. Gunn, Azadah Firouzian, Jennifer Lawson, Giovanna Zamboni, Basil Ridha, Barbara J. Sahakian, James B. Rowe, Alan Thomas, Lynn Rochester, Dominic Ffytche, Robert Howard, Henrik Zetterberg, Clare MacKay and Simon Lovestone

[Journal of Alzheimer's Disease 60(1), 2017, 283-293, DOI 10.3233/JAD-170129

https://content.iospress.com/articles/journal-of-alzheimers-disease/jad170129

On page 288, in Fig. 2, the images for $\mathrm{C}$ and $\mathrm{D}$ were reversed, and the labelling on $\mathrm{D}$ should be $p<0.1$ rather than $p<0.01$. For consistency the labelling on $\mathrm{B}$ has been changed to $p<0.1$ (prom $p=0.06$ ) and a minor inaccuracy in the $R$ value in $B$ has been rectified ( $R$ value of 0.56 instead of 0.55 ).
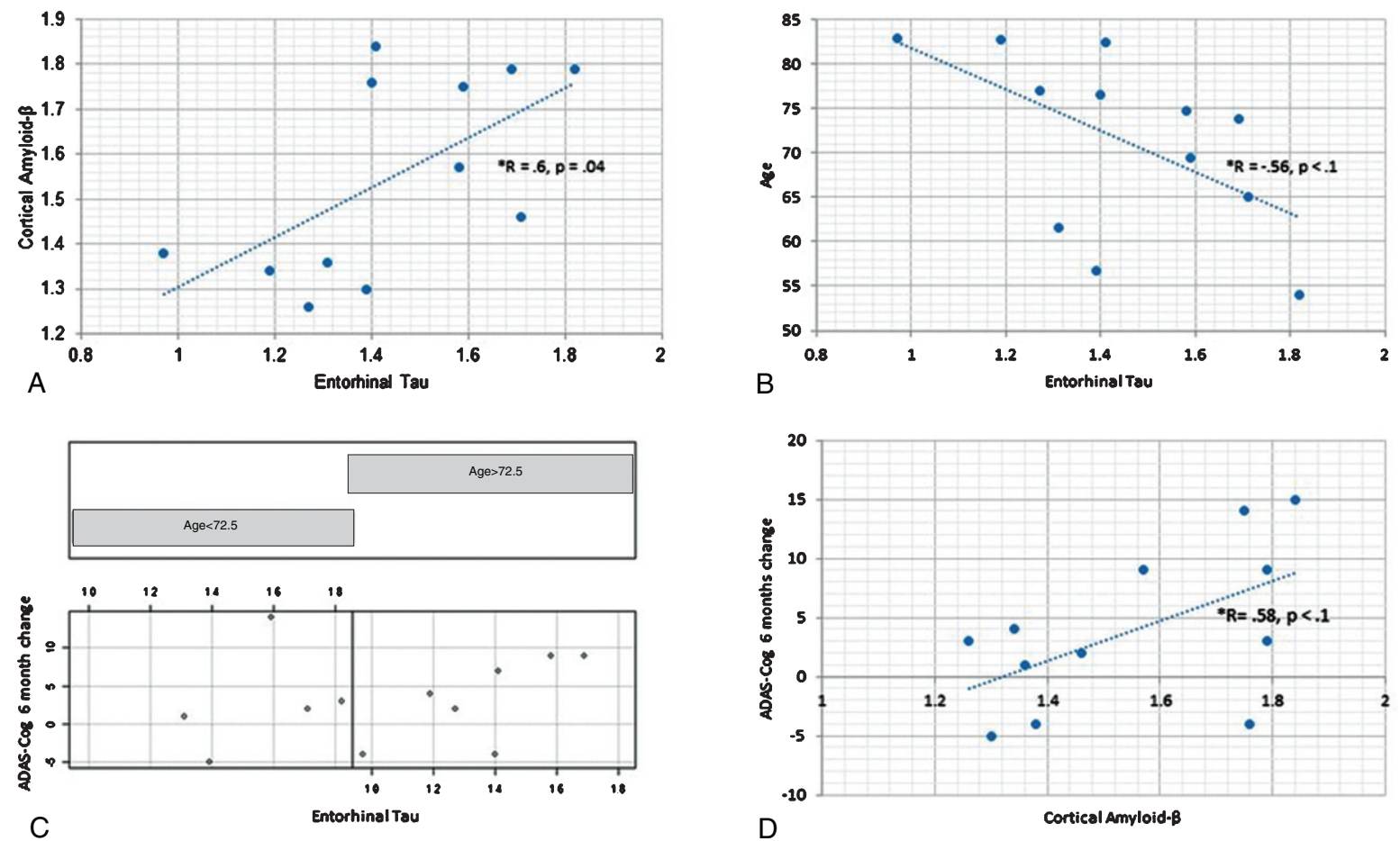